\title{
Identification, analysis, and linkage mapping of expressed sequence tags from the Australian sheep blowfly
}

Siu F Lee ${ }^{1 *}$, Zhenzhong Chen ${ }^{1 \dagger}$, Annette McGrath ${ }^{2}$, Robert T Good ${ }^{1}$ and Philip Batterham ${ }^{1}$

\begin{abstract}
Background: The Australian sheep blowfly Lucilia cuprina (Wiedemann) (Diptera: Calliphoridae) is a destructive pest of the sheep, a model organism for insecticide resistance research, and a valuable tool for medical and forensic professionals. However, genomic information on L. cuprina is still sparse.

Results: We report here the construction of an embryonic and 2 larval CDNA libraries for L. cuprina. A total of 29,816 expressed sequence tags (ESTs) were obtained and assembled into 7,464 unique clusters. The sequence collection captures a great diversity of genes, including those related to insecticide resistance (e.g., 12 cytochrome P450s, 2 glutathione $S$ transferases, and 6 esterases). Compared to Drosophila melanogaster, codon preference is different in 13 of the 18 amino acids encoded by redundant codons, reflecting the lower overall GC content in $L$. cuprina. In addition, we demonstrated that the ESTs could be converted into informative gene markers by capitalizing on the known gene structures in the model organism D. melanogaster. We successfully assigned 41 genes to their respective chromosomes in L. cuprina. The relative locations of these loci revealed high but incomplete chromosomal synteny between L. cuprina and D. melanogaster.
\end{abstract}

Conclusions: Our results represent the first major transcriptomic undertaking in L. cuprina. These new genetic resources could be useful for the blowfly and insect research community.

\section{Background}

The Australian sheep blowfly Lucilia cuprina (Wiedemann) (Diptera: Calliphoridae) is an important biological tool for medical treatment and forensic investigation. Disinfected blowfly larvae are routinely used in maggot debridement therapy to promote wound healing [1-3]. The necrophagous nature of L. cuprina also makes it invaluable for forensic analysis, particularly in estimating postmortem interval [4]. In contrast to these beneficial roles, L. cuprina is the primary cause of flystrike in Australia and New Zealand [5,6]. The practice of surgical mulesing, as well as various chemical insecticides, has been used to control this formidable pest. However, fly populations often evolved resistance rapidly [7-10].

\footnotetext{
* Correspondence: ronaldl@unimelb.edu.au

+ Contributed equally

${ }^{1}$ Centre for Environmental Stress and Adaptation Research, Bio21 Institute, Genetics Department, University of Melbourne, 30 Flemington Road, Parkville, VIC 3010, Australia

Full list of author information is available at the end of the article
}

Research into the genetic and biochemical mechanisms of resistance has provided some of the best examples of genetic adaptation to selection [11-13].

Despite its medical and agronomical importance and its historical status as one of the model organisms in insecticide resistance research, genomic information on L. cuprina is still relatively sparse. The haploid genome is approximately 810 mega bases [14], which is about 5 times the genome size of Drosophila melanogaster. Polytene in situ hybridization and genetic mapping studies have determined the basic organization of its 6 chromosomes [15-17]. In 1993, Weller and Foster published a recombination map based on 72 morphological and enzyme markers, and this remains the most comprehensive linkage map of L. cuprina to date [18]. The chromosomal location of these markers indicates that the major linkage elements (i.e., Muller's Elements) remain relatively conserved in higher Diptera [18].

To combat this insect pest more intelligently, it is desirable to improve our knowledge of its genetic makeup. 
Molecular tools have become increasingly accessible to generate large amount of information in a cost-effective manner. As the per-base cost of DNA sequencing continues to fall, large-scale expressed sequence tag (EST) projects have been accomplished in many insect species, and thousands of ESTs have been deposited in public databases, including higher dipteran species such as the screwworm Cochliomyia hominivorax [19] and the tsetse fly Glossina morsitans [20].

This paper describes a similar gene discovery effort to identify transcripts expressed in preadult stages (embryonic and larval). An assembly of 7,464 unique gene clusters was produced from a total of 29,816 ESTs. The protein-coding contents of this non-redundant dataset were evaluated via a series of homology analyses. We short-listed a subset of these L. cuprina genes, which showed high sequence conservation, favorable gene structure (suitable exon/intron positions and sizes), and single correspondence in the $D$. melanogaster and Anopheles gambiae genomes. To demonstrate their usefulness in comparative mapping, we carried out chromosomal assignment of 41 genes to infer interchromosomal rearrangements. Comparison between $L$. cuprina and D. melanogaster revealed a high but incomplete chromosomal synteny. This newly generated EST dataset is a significant step in the systematic buildup of genomic resources for this important insect in agricultural and medical entomology.

\section{Results}

\section{Characteristics of EST assembly}

We obtained 13,666 embryonic (JG422424-JG436089), 14,640 first-instar (JG407784-JG422423), and 880 thirdinstar (JG406904-JG407783) ESTs. The combined dataset $(29,186$ ESTs) was assembled into 7,464 unique clusters (Additional file 1), comprising 2,797 contigs and 4,667 singletons (Figure 1). The basic features of the sequence assembly are summarized in Figures 2 and 3. The majority $(65.5 \%)$ of the 7,464 sequences were 500 900 bases in length (Figure 2), and the number of EST reads in a contig ranged between 2 and 3,700 (Figure 3), with an average of 8.8 reads (median $=3$ ) per contig.

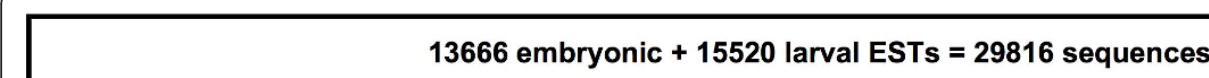

equences

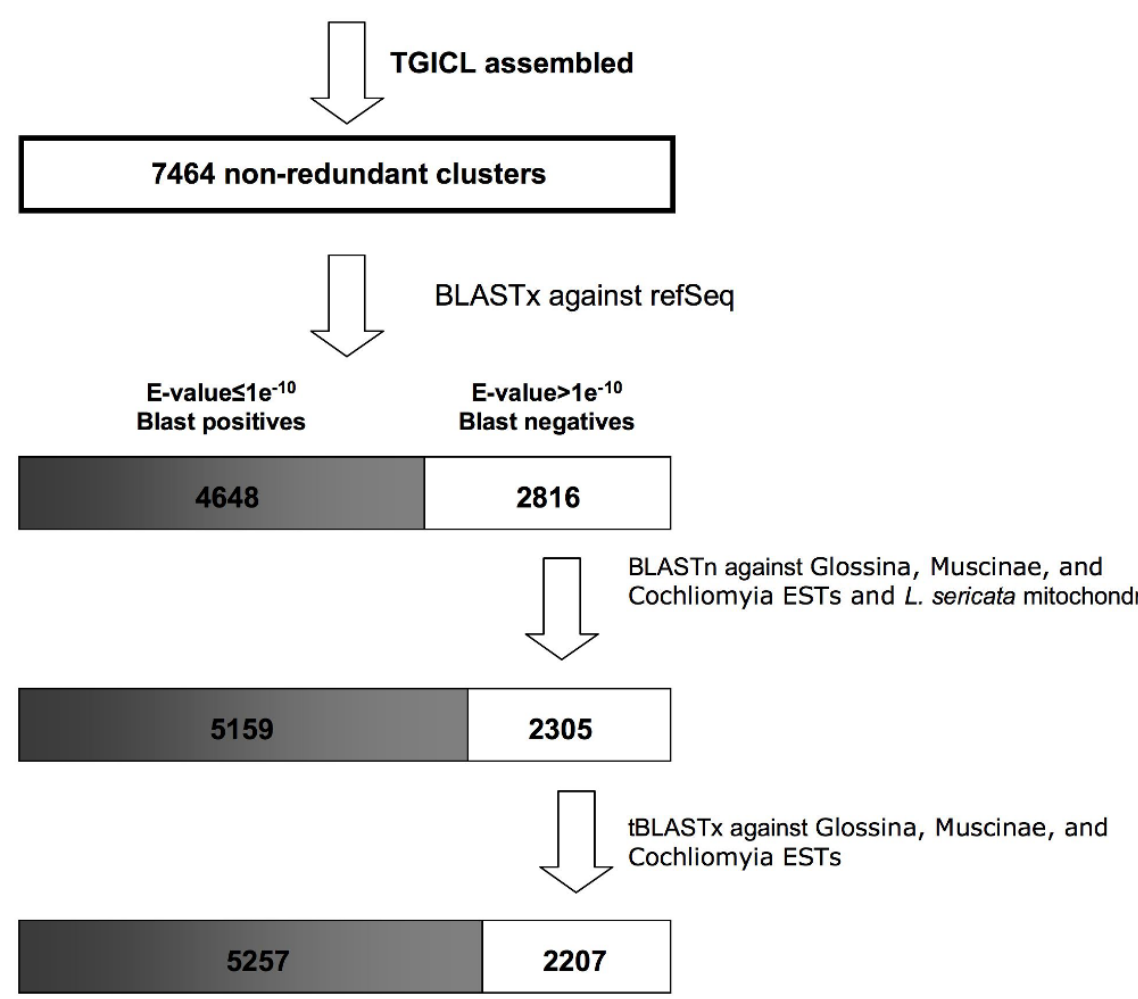

Figure 1 An overview of the acquisition, assembly, analysis, and application of L. cuprina-expressed sequence tags. A total of 29,816 ESTs from embryonic and larval libraries was assembled into 7,464 unique sequence clusters using the TGICL procedures. E-values from BLAST searches were arranged in ascending order from left to right, indicated by the darkness of shade. 


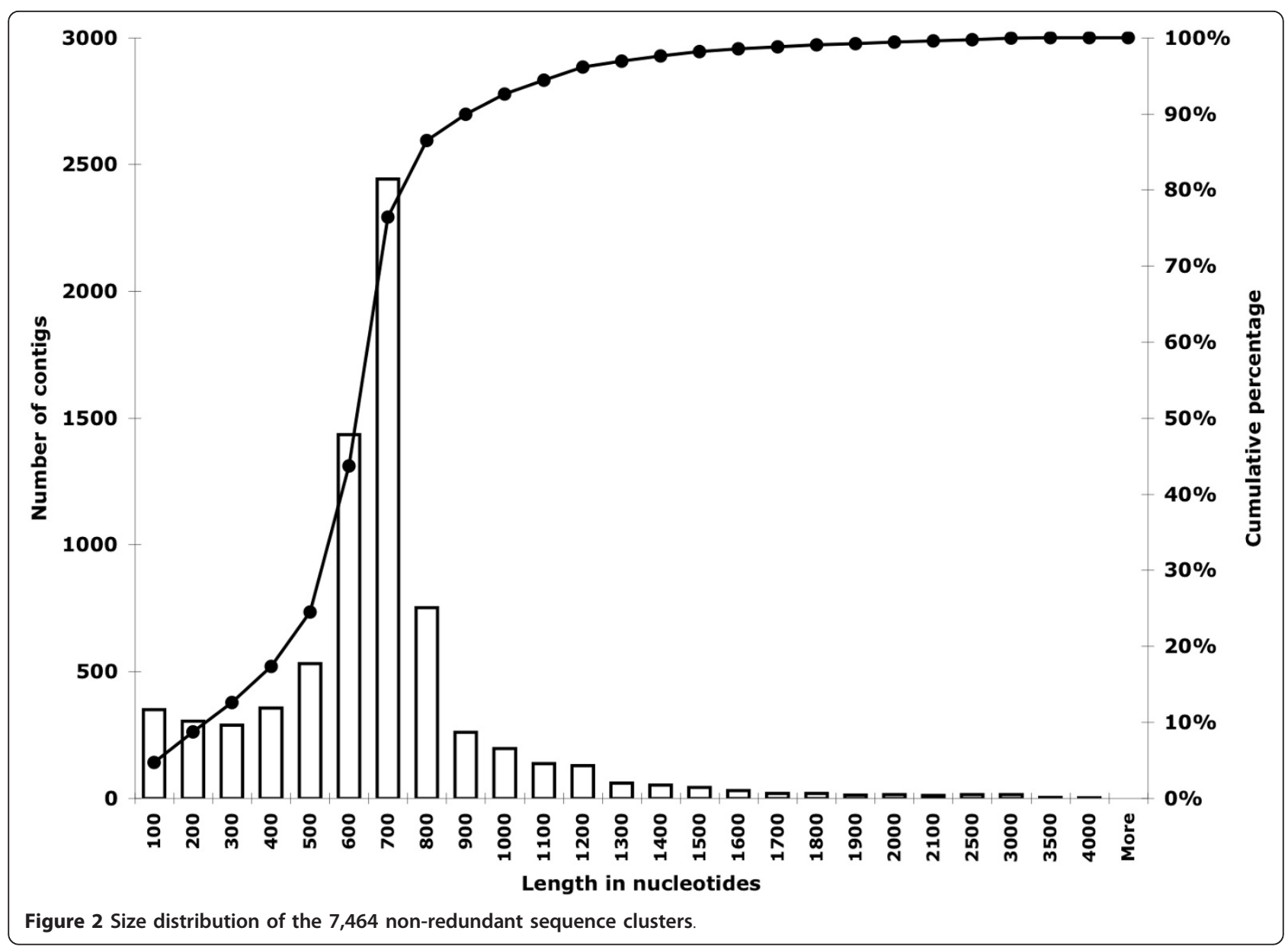

Abundant transcripts in embryonic and larval stages Since the cDNA libraries were not normalized, the number of reads in contigs can be used as an indication of levels of gene expression. Table 1 summarizes information about the most abundantly expressed genes, defined as contigs containing more than 100 ESTs. The mitochondria-derived transcripts dominate this list, accounting for a total of 5,275 ESTs, or $17 \%$ of the entire EST collection. In comparison to the published Lucilia sericata mitochondrial genome [21], our ESTs captured 12 protein coding genes and the $16 \mathrm{~S}$ rRNA gene (Additional file 2). In addition to mitochondrial transcripts, various ribosomal protein genes ( $R p L 6, R p L 7 A, R p L 7$, $R p L 4$, and $R p S 3 A$ ), $18 S r R N A$, and elongation factors (ef1- $\alpha$, ef2, and ef1- $\gamma$ ) were also amongst the most highly expressed genes (Table 1), reflecting the robust translation and protein synthesis processes in the embryonic and larval stages.

\section{GC content and codon usage bias}

Based on results from a set of 200 conserved genes (Additional file 3 ), the average GC content (mean \pm standard deviation) per coding sequence (CDS) is $0.4344 \pm 0.0433$ in L. cuprina and $0.5654 \pm 0.0418$ in D. melanogaster. The effective number of codons (Nc) is 43.81 in L. cuprina and 40.89 in D. melanogaster. Compared to D. melanogaster, L. cuprina shows a different codon preference for 13 of the 18 amino acids encoded by redundant codons (Table 2). The most noticeable changes occur in the preferred codons for glutamine $(\mathrm{Q})$, glutamic acid $(\mathrm{E})$, and leucine (L).

\section{Protein-coding contents of EST assembly}

To evaluate the protein coding contents of our ESTs, the 7,464 non-redundant sequences were subject to various homology searches against existing sequences (Figure 1). Our homology analyses showed that 5,257 (70\%) of the non-redundant sequences had significant $\left(E-v a l u e ~ \leq 1 e^{-10}\right)$ matches in the public domains (Additional file 4). The sequences that had recognizable homologs constituted 937 InterProScan and 494 Gene Ontology terms (Additional files 5 and 6), indicating that a great diversity of protein motifs and biological processes was represented in our dataset. We also estimated that $\sim 78 \%$ (205 of 262) of the existing L. cuprina nucleotide sequences in Genbank were represented in our EST collection. Our Lucilia ESTs 


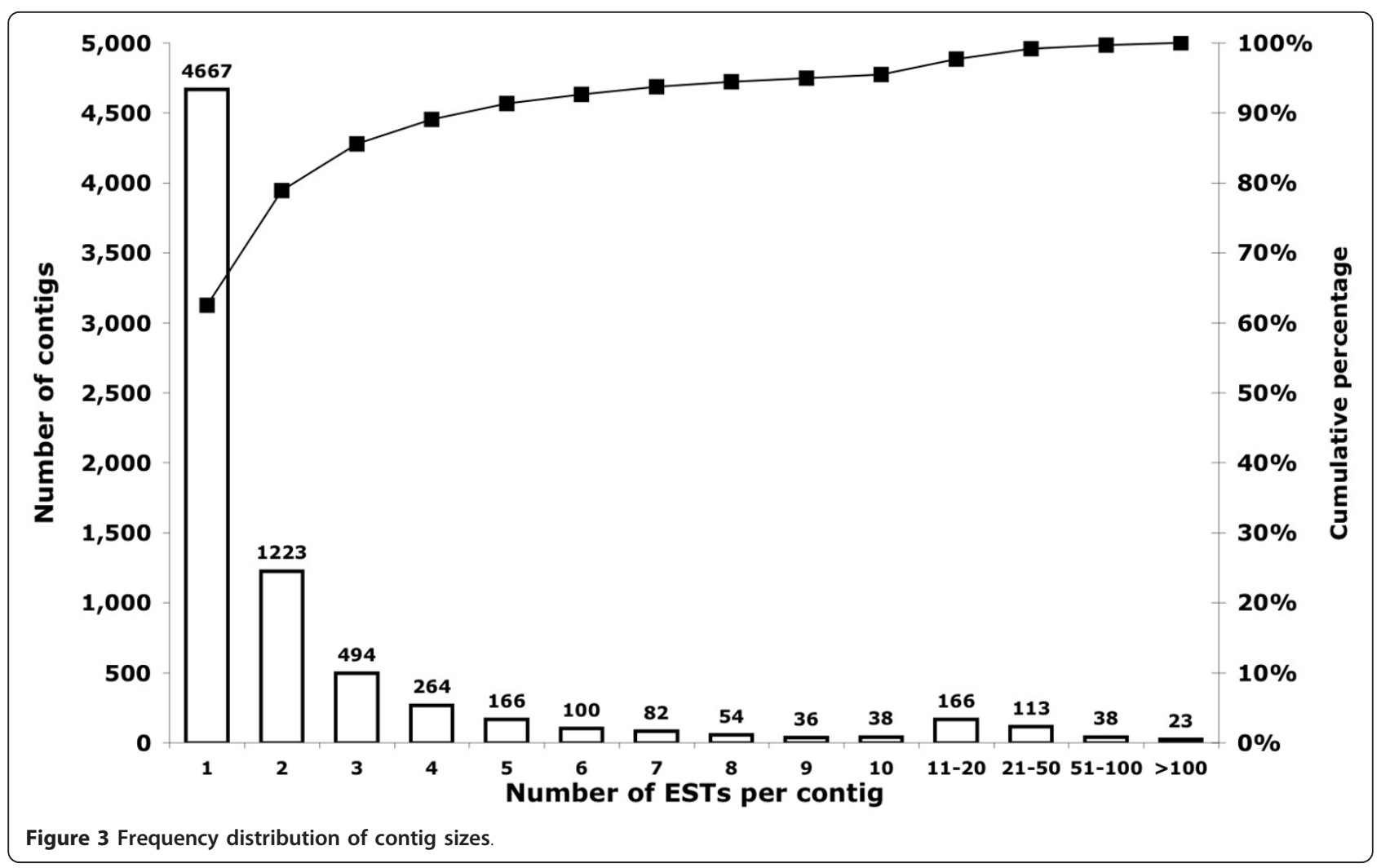

Table 1 The most highly expressed genes in the EST dataset, indicated by the number of ESTs in a contig

\begin{tabular}{|c|c|c|c|}
\hline Contig name & $\begin{array}{l}\text { Contig } \\
\text { length (nt) }\end{array}$ & $\begin{array}{l}\text { No. of EST reads } \\
\text { in contig }\end{array}$ & Description \\
\hline lucilia_CL1Contig5 & 1972 & 3700 & Mitochondrial 16S rRNA and 12S rRNA \\
\hline lucilia_CL4Contig1 & 1560 & 679 & $\begin{array}{l}\text { Mitochondrial COI gene for cytochrome oxidase I and COII } \\
\text { gene for cytochrome oxidase II }\end{array}$ \\
\hline lucilia_CL3Contig2 & 2845 & 382 & Elongation factor 1-alpha \\
\hline lucilia_CL3Contig3 & 995 & 382 & Ribosomal protein L6 (RpL6) \\
\hline lucilia_CL6Contig3 & 878 & 258 & Mitochondrial cytochrome-c oxidase subunit III \\
\hline lucilia_CL7Contig2 & 1272 & 253 & Mitochondrial cytochrome b \\
\hline lucilia_CL5Contig3 & 3993 & 179 & 18S ribosomal RNA gene \\
\hline lucilia_CL2Contig20 & 1065 & 168 & Myosin regulatory light chain 2 \\
\hline lucilia_CL10Contig1 & 1804 & 163 & Tubulin alpha-1 chain \\
\hline lucilia_CL5Contig4 & 2551 & 158 & Heat shock $70 \mathrm{kDa}$ protein cognate 4 \\
\hline lucilia_CL11Contig1 & 1187 & 157 & Ribosomal protein L7a (RpL7A) \\
\hline lucilia_CL3Contig8 & 2596 & 153 & Mitochondrial ATP synthase alpha subunit \\
\hline lucilia_CL12Contig1 & 1214 & 133 & ADP/ATP translocase \\
\hline lucilia_CL13Contig2 & 2815 & 125 & Arcl-like zinc binding protein (nucleic acid binding) \\
\hline lucilia_CL2Contig7 & 2905 & 122 & Elongation factor 2 \\
\hline lucilia_CL2Contig49 & 763 & 119 & Mitochondrial ATP synthase lipid-binding protein \\
\hline lucilia_CL2Contig52 & 2285 & 114 & ATP-dependent RNA helicase p62 (nucleic acid binding) \\
\hline lucilia_CL17Contig1 & 742 & 113 & $\begin{array}{l}\text { Mitochondrial COI gene for cytochrome oxidase I and COII } \\
\text { gene for cytochrome oxidase II }\end{array}$ \\
\hline lucilia_CL16Contig1 & 1199 & 112 & Ribosomal protein L7 (RpL7) \\
\hline lucilia_CL14Contig2 & 1780 & 110 & Elongation factor 1-gamma \\
\hline lucilia_CL20Contig1 & 1472 & 110 & Ribosomal protein L4 (RpL4) \\
\hline lucilia_CL21Contig1 & 1095 & 107 & Ribosomal protein S3a (RpS3A) \\
\hline lucilia_CL19Contig2 & 1124 & 103 & Translationally controlled tumor protein \\
\hline
\end{tabular}


Table 2 Codon usage comparison between L. cuprina and D. melanogaster based on $\mathbf{2 0 0}$ conserved genes

\begin{tabular}{|c|c|c|c|c|c|}
\hline \multirow[b]{2}{*}{ Amino acid } & \multirow[b]{2}{*}{ Codon } & \multicolumn{2}{|c|}{ L. cuprina } & \multicolumn{2}{|c|}{ D. melanogaster } \\
\hline & & Fraction & Number & Fraction & Number \\
\hline Ala (A) & GCA & 0.094 & 350 & 0.088 & 337 \\
\hline Ala (A) & GCC & 0.398 & 1480 & $\underline{0.602}$ & 2308 \\
\hline Ala (A) & GCG & 0.021 & 77 & $\overline{0.114}$ & 436 \\
\hline Ala (A) & $\mathrm{GCT}$ & 0.487 & 1812 & 0.196 & 751 \\
\hline Cys (C) & TGC & 0.514 & 390 & $\underline{0.831}$ & 582 \\
\hline Cys (C) & TGT & 0.486 & 369 & 0.169 & 118 \\
\hline Asp (D) & GAC & 0.264 & 681 & $\underline{0.533}$ & 1371 \\
\hline Asp (D) & GAT & $\underline{0.736}$ & 1897 & 0.467 & 1200 \\
\hline Glu (E) & GAA & 0.791 & 2582 & 0.202 & 652 \\
\hline Glu (E) & GAG & 0.209 & 684 & $\underline{0.798}$ & 2581 \\
\hline Phe (F) & TTC & $\underline{0.62}$ & 1090 & $\underline{0.814}$ & 1429 \\
\hline Phe (F) & $\pi T$ & 0.38 & 667 & 0.186 & 327 \\
\hline Gly (G) & GGA & 0.121 & 407 & 0.223 & 742 \\
\hline Gly (G) & GGC & 0.253 & 850 & $\underline{0.496}$ & 1652 \\
\hline Gly (G) & GGG & 0.015 & 49 & 0.031 & 102 \\
\hline Gly (G) & GGT & $\underline{0.611}$ & 2050 & 0.251 & 837 \\
\hline His $(H)$ & CAC & 0.485 & 458 & $\underline{0.689}$ & 648 \\
\hline His $(H)$ & CAT & 0.515 & 486 & $\overline{0.311}$ & 293 \\
\hline Ile (I) & ATA & 0.123 & 335 & 0.073 & 192 \\
\hline Ile (I) & ATC & 0.333 & 903 & $\underline{0.644}$ & 1692 \\
\hline Ile (I) & ATT & 0.544 & 1475 & 0.283 & 742 \\
\hline Lys (K) & AAA & 0.518 & 2101 & 0.147 & 572 \\
\hline Lys (K) & AAG & 0.482 & 1958 & $\underline{0.853}$ & 3316 \\
\hline Leu (L) & CTA & 0.049 & 194 & 0.043 & 170 \\
\hline Leu (L) & CTC & 0.075 & 297 & 0.165 & 661 \\
\hline Leu (L) & $\mathrm{CTG}$ & 0.038 & 149 & $\underline{0.552}$ & 2208 \\
\hline Leu (L) & $\mathrm{CTT}$ & 0.113 & 445 & 0.07 & 281 \\
\hline Leu (L) & TTA & 0.167 & 657 & 0.02 & 79 \\
\hline Leu (L) & TTG & 0.558 & 2195 & 0.15 & 600 \\
\hline Met (M) & ATG & 1 & 1208 & 1 & 1092 \\
\hline Asn (N) & AAC & 0.431 & 993 & 0.738 & 1538 \\
\hline Asn (N) & AAT & $\underline{0.569}$ & 1311 & 0.262 & 546 \\
\hline Pro (P) & CCA & 0.277 & 563 & 0.185 & 375 \\
\hline Pro (P) & $\mathrm{CCC}$ & $\underline{0.451}$ & 916 & $\underline{0.499}$ & 1013 \\
\hline Pro (P) & CCG & 0.031 & 64 & 0.226 & 460 \\
\hline Pro (P) & $\mathrm{CCT}$ & 0.241 & 490 & 0.09 & 183 \\
\hline Gln (Q) & CAA & 0.801 & 1529 & 0.178 & 346 \\
\hline Gln (Q) & CAG & 0.199 & 381 & $\underline{0.822}$ & 1595 \\
\hline Arg (R) & AGA & 0.145 & 386 & 0.044 & 120 \\
\hline $\operatorname{Arg}(\mathrm{R})$ & AGG & 0.028 & 74 & 0.074 & 200 \\
\hline $\operatorname{Arg}(\mathrm{R})$ & CGA & 0.033 & 89 & 0.064 & 172 \\
\hline $\operatorname{Arg}(\mathrm{R})$ & CGC & 0.223 & 595 & $\underline{0.48}$ & 1297 \\
\hline $\operatorname{Arg}(\mathrm{R})$ & CGG & 0.009 & 24 & 0.08 & 217 \\
\hline $\operatorname{Arg}(\mathrm{R})$ & CGT & $\underline{0.562}$ & 1498 & 0.258 & 696 \\
\hline Ser (S) & AGC & 0.117 & 312 & 0.219 & 593 \\
\hline Ser $(S)$ & AGT & 0.141 & 376 & 0.062 & 168 \\
\hline Ser $(S)$ & TCA & 0.152 & 405 & 0.05 & 135 \\
\hline Ser $(S)$ & TCC & 0.253 & 675 & 0.343 & 929 \\
\hline Ser (S) & TCG & 0.089 & 238 & 0.234 & 635 \\
\hline
\end{tabular}

Table 2 Codon usage comparison between L. cuprina and D. melanogaster based on 200 conserved genes (Continued)

\begin{tabular}{llllll}
\hline Ser (S) & TCT & 0.247 & 659 & 0.093 & 251 \\
Thr (T) & ACA & 0.201 & 493 & 0.107 & 259 \\
Thr (T) & ACC & $\underline{0.431}$ & 1055 & $\underline{0.587}$ & 1421 \\
Thr (T) & ACG & 0.03 & 74 & 0.175 & 424 \\
Thr (T) & ACT & 0.337 & 825 & 0.131 & 316 \\
Val (V) & GTA & 0.218 & 733 & 0.052 & 174 \\
Val (V) & GTC & 0.24 & 806 & 0.31 & 1046 \\
Val (V) & GTG & 0.126 & 424 & $\underline{0.491}$ & 1657 \\
Val (V) & GT & $\underline{\mathbf{0 . 4 1 6}}$ & 1400 & 0.147 & 495 \\
Trp (W) & TGG & $\underline{1}$ & 430 & 1 & 438 \\
Tyr (Y) & TAC & 0.455 & 666 & $\underline{0.771}$ & 1099 \\
Tyr (Y) & TAT & $\underline{\mathbf{0 . 5 4 5}}$ & 799 & 0.229 & 326 \\
STOP & TAA & $\underline{0.785}$ & 157 & $\underline{0.6}$ & 120 \\
STOP & TAG & $\underline{0.125}$ & 25 & 0.31 & 62 \\
STOP & TGA & 0.09 & 18 & 0.09 & 18 \\
Total & & & 47579 & & 47095 \\
\hline The & & &
\end{tabular}

The preferred codons for each amino acid are in underlined in each species; cases where the preferred codons in L. cuprina are different from those of $D$. melanogaster are indicated in bold.

matched 3,280 unique D. melanogaster genes (from 3,409 unique polypeptides) at $\mathrm{E}$-value $\leq 1 \mathrm{e}^{-10}$; this is equivalent to $\sim 24.1 \%$ of the total gene count in D. melanogaster (assuming the total number of genes is $\sim 13,600$ ).

\section{Identification of potential detoxification and insecticide target genes}

We identified 12 cytochrome P450 (Cyp12a5, Cyp12d1, Cyp302a1 or disembodied, Cyp307a1 or spook, Cyp317a1, Cyp4d2, Cyp4g15, Cyp6a13, Cyp6d2, Cyp6d4, Cyp6d5, and Cyp9f2), 2 glutathione S-transferase (GstD1 and GstS1), and 6 esterase (Glt, Nrt, CG9289, alphaEst5, CG9287, and alpha-Est7) homologs in the L. cuprina (Table 3). In addition to these detoxification gene families, we also identified ESTs encoding target proteins that have previously been implicated in insecticide resistance (see [22-25]). These included homologs of the gamma-aminobutyric acid receptor-associated protein $(\mathrm{GABA}(\mathrm{A})$ receptor-associated protein; $\mathrm{EST}=$ GI: 333428695), glutamate receptor ionotropic kainate 2 (glutamate receptor 6; EST = GI: 333421827), and a probable sodium channel protein type 9 subunit alpha $(\mathrm{EST}=\mathrm{GI}: 333416352)$.

\section{Blast negatives in EST assembly}

As of July 2010, 2,207 of the 7,464 unique gene clusters did not match any sequences in the public databases. Three hundred and sixty-five (or 16.5\%) of these blast negatives had an ORF (minimum 20 codons), and the average length of their hypothetical polypeptide products 
Table 3 Identification of potential detoxification genes in L. cuprina

\begin{tabular}{cc}
\hline D. melanogaster P450*, GST* or esterase genes & Representative L. cuprina EST (GI number) \\
\hline Cyp12a5 & 333435397 \\
Cyp12d1 & 333437090 \\
Cyp307a1 (spook) & 333440339 \\
Cyp317a1 & 333412120 \\
Cyp4d2 & 333429047 \\
Cyp4g15 & 333426288 \\
Cyp6a13 & 333425740 \\
Cyp6d2 & 333435119 \\
Cyp6d4 & 333415889 \\
Cyp6d5 & 333432766 \\
Cyp9f2 & 333432767 \\
GstD1 & 333420943 \\
GstS1 & 333426230 \\
Glt & 333429052 \\
Nrt & 333415214 \\
CG9289 & 333422289 \\
alpha-Est5 & 333425114 \\
alpha-Est7 & 333429048 \\
\hline
\end{tabular}

*P450 (cytochrome P450); GST (gluathione S transferase).

was 126 amino acids (median $=126$ amino acids; range $=$ 20-584 amino acids) (details, see Additional file 7).

\section{Anchor loci development and chromosomal synteny in higher Diptera}

One aim of the current EST project was to identify single-copy genes that are highly conserved between species for synteny comparison. Reciprocal homology searches among L. cuprina, D. melanogaster, and $A$. gambiae yielded a set of reciprocal best-hit trios, and 298 of such trios had favorable intron position and size range in $D$. melanogaster (Additional file 8 ). This list of 298 orthologous groups facilitated our ongoing linkage map construction in L. cuprina. We successfully assigned 41 gene markers to 5 linkage groups using a male informative pedigree by scoring intron length polymorphisms (Figure 4). Comparison between L. cuprina and D. melanogaster based on 41 gene markers revealed a high level of synteny, although several deviations were also evident (Figure 5; Additional file 9). Deviations included inx3 RpL30, CG3564, RpS13, and $R p L 15$., A potential translocation or fusion/dissociation event was identified between the smallest chromosome (Muller F in Drosophila) and an autosome (Muller D in Lucilia), as suggested by the location of RpS3A (Figure 5).

\section{Discussion}

The main outcome of this project is the significant improvement of the gene inventory for the Australian sheep blowfly Lucilia cuprina. Amongst other applications, this new resource presents promising benefits to such areas as medical, forensic, pest control, and the understanding of genetic adaptation to insecticides.

Barring major gene expansion or contraction, and assuming that $L$. cuprina has the same number of genes as in D. melanogaster $(\sim 13,600)$ [26], the 7,464 unique gene clusters we found in our EST libraries would account for up to $55 \%$ of the genes present in the species. The actual percentage is much lower due to (but not limited to) the TGICL assembly parameters and the presence of $4.7 \%$ short ( $\leq 100$ bases) sequences (Figure 2 ). An estimate of $24.1 \%$ gene coverage was obtained by limiting homology comparison to L. cuprina and D. melanogaster. However, fast-evolving genes and gene families that have been expanded in the blowfly lineage are under-represented in this analysis. Hence, the estimate of $24.1 \%$ could be considered the lower bound of total gene coverage. Nonetheless, this is a conservative yet reasonable estimation given that our cDNA libraries were not experimentally normalized and that only preadult developmental stages contributed to the transcript pool. The EST sequences contain a large number of 


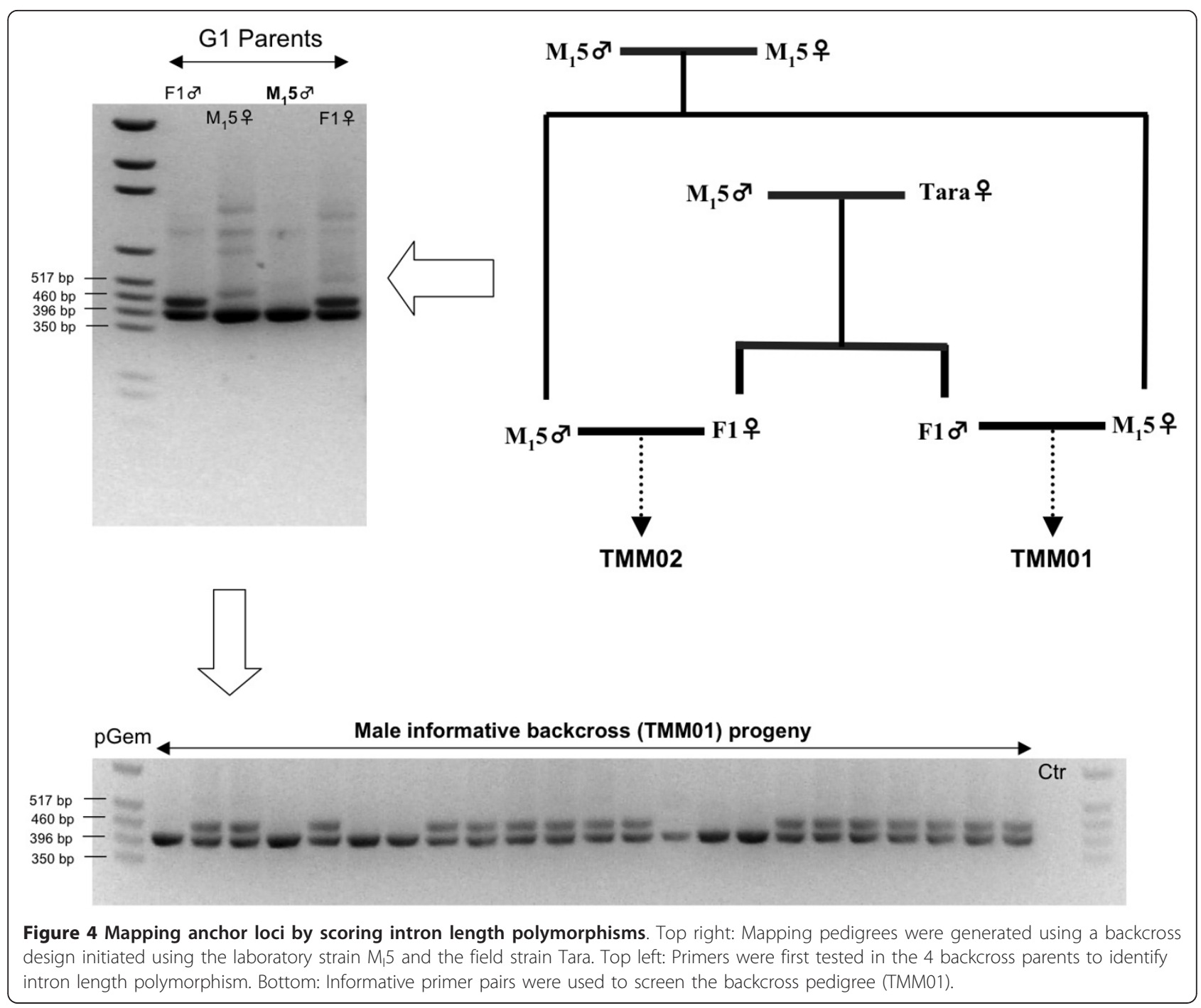

recognizable protein motifs, as suggested by InterProScan results (Additional file 5), whose protein products are likely to participate in a myriad of biological and cellular processes, as also suggested by Gene Ontology analysis (Additional file 6).

Compared to D. melanogaster, L. cuprina appears to have low GC content and a different codon preference for many amino acids. Despite the fact that the comparison was based on 200 conserved gene homologs, the codon preferences for $D$. melanogaster are consistent with those reported by Vicario et al. [27]. The higher effective Nc in $L$. cuprina (43.81) than D. melanogaster (40.89) suggests a weaker selection constraint on codon usage in L. cuprina, at least for these highly conserved genes. It is noted that the 200 sequence pairs analyzed represent only a small fraction (1.5\%) of the coding sequences in the 2 species; perhaps a different pattern might emerge when less-conserved gene homologs are included. Nevertheless, these results could be useful for training gene-finding algorithms and the analysis of the full genome sequence when it becomes available.

The acquisition of $>3,280$ blowfly genes allows more sophisticated experimental systems to be developed in the future. Aside from the improvement in the knowledge about the genetic composition of the species, the dataset provides a foundation for designing gene-based microarrays for expression profiling. Furthermore, the plasmid collections can also serve as a permanent source of cDNA clones for protein expression, in situ hybridization, and even for transgenic manipulation such as those described in [28-30]. The sequence knowledge of the housekeeping genes such as the ribosomal protein genes, tubulin, and actin could serve as internal controls for quantitative realtime PCR. In fact, the need for such reference genes was recently discussed in [31]. The availability of the L. cuprina cDNA sequences would also facilitate quantification of 
expression profiles of many genes of interest, bypassing the time-consuming gene discovery steps. It is expected that our EST collection will be invaluable for annotating the genic regions of the L. cuprina genome, when it is eventually sequenced. Conversely, the cDNA information could itself serve as a gene database, such that short peptides generated by the high-throughput proteome sequencing, similar to those reported in the brain tissues of another blowfly, Protophormia terraenovae [32], could be compared, forming a transcriptomic-proteomic feed-forward loop.

We identified genes that are related to insecticide resistance in L. cuprina (Table 3). Isolation of these homologs in L. cuprina would allow their expression patterns to be accurately measured (e.g., by real-time PCR), and their roles in insecticide resistance to be evaluated. PCR assays to screen for naturally occurring DNA polymorphisms (e.g., exon-primed intron-crossing (EPIC) markers) could also be developed to monitor the temporal and spatial distribution of different alleles. While many of their D. melanogaster homologs have been implicated in insecticide detoxification [33-36], some of the genes identified are involved in other developmental processes such as ecdysone biosynthesis (disembodied and spook) [37,38] and brain function/development (Cyp4g15) [39]. The proportions of the new L. cuprina homologs represent only a small fraction of these 3 detoxification gene families (see [40-42]). With the advent of next-generation sequencing (NGS) technologies, large-scale genome or transcriptome sequencing has become increasingly popular. For example, transcriptomic analyses using NGS have now been reported in many non-model insect species [43-48]. Similar approaches could be extended to $L$. cuprina and other related blowfly species, to enable a more comprehensive assessment of novel insecticide targets.

Another important application of our newly identified ESTs was to improve the genetic map of L. cuprina. ESTs can be converted to a set of anchor loci for linkage mapping, as has been repeatedly shown in other insects $[49,50]$. We adopted a conservative "reciprocal best hit with strong homology" strategy in the selection of homologous markers, in which $D$. melanogaster served as the primary reference. A. gambiae, which diverged from the Lucilia and Drosophila lineages about 250 MYA, acted as an outgroup to improve the confidence in orthology calling, as sequence homology needed to reach the E-value of $\leq 1 \mathrm{e}^{-50}$ threshold to be considered further. In other words, we opted for 
confidence rather than sensitivity in our search for orthologous markers.

The EST-derived markers constituted a substantial proportion of anchor loci in the present study and were useful for inferring chromosomal synteny (Figure 5). Linkage assignment of 41 markers allowed us to conclude that chromosomal synteny is high between the Lucilia and Drosophila lineages. Our results are typical for higher dipteran species, as suggested by previous studies $[17,51,52]$. Several chromosomal fusion/dissociation events have nonetheless been documented within the Drosophila genus. For example, the fusion of $\mathrm{Chr} 4$ (Muller's element F) to an autosome was found in Drosophila willistoni [53]. Moreover, comparison between mosquito and Drosophila reveals that patches of syntenic regions are scattered across many chromosome regions [54]. Our mapping results suggested that gene content on each of the Muller's elements in L. cuprina can, to a large extent, be predicted from the D. melanogaster map. However, the obvious cases of synteny violation (Figure 5; Additional file 9) would mean that direct extrapolation of linkage information from $D$. melanogaster would require extra caution. The interspecies differences should justify future de novo construction of linkage maps for L. cuprina, with denser markers.

The 298 putative orthologs effectively form a pipeline for future comparative mapping efforts (Additional file 8). Their chromosome addresses in D. melanogaster span virtually all regions of the genome, allowing flexible control over marker density for genomic regions of interest. Several chromosomal areas in Lucilia are of significant historical importance: the Scallop/Notch $[55,56]$ on chromosome II and the Rop-1 [12,57] regions on chromosome IV. In fact, several gene markers generated in the present study have already been utilized to understand the patterns of selective sweeps around the Rop-1 locus [58]. The marker pipeline also offers a starting point for fine scale mapping of the fitness modifier locus $(M)$, which is believed to counter the fitness disadvantage of the diazinon-resistant flies in the absence of insecticide [59-61]. Together with an appropriate genomic library, these newly acquired ESTs provide an ample supply of markers for positional cloning of the $M$ locus.

The evolutionary origin and phylogeny relationship among blowfly species has been of great interest to many researchers, owing to its medical and forensic implications $[62,63]$. With the much expanded gene repertoire, some of the L. cuprina genes identified here, especially those that show least similarity to other known sequences could be utilized to develop species diagnostic assays. The current EST sequences would greatly complement such an exploration.
While the assemblage of 29,816 ESTs into 7,464 was straight forward, the interpretation of the information contents requires regular re-adjustment, in light of the constantly expanding sequence databases in other species. In order to evaluate the coding components of the newly acquired sequences, they were sorted according to the level of homology to their counterparts in the Genbank reference protein database, producing a typical BLAST significance spectrum (Figure 1). It is anticipated that such a spectrum would change over time. As new sequences from other organisms become publicly accessible, it would simultaneously alter the structure of the existing sequence databases and hence the BLAST results. The recently released EST collections $(116,737$ reads) from 3 closely related taxa (Glossina, Cochliomyia and, Muscinae) clearly illustrate this notion (Figure 1).

Given that the number of non-redundant sequence clusters depends largely on the assembly settings, the " $90 \%$ identity over 50 bases" requirement could be viewed as a balanced option, but might not be an optimized condition for all genes. One indication is the presence of residual sequence redundancy in the dataset, presumably due to the natural existence of splice variants, transcript isoforms, natural polymorphisms, or genuine gene families. Hence, it is worthwhile to disassemble relevant contigs that belong to the gene of interest and find the most appropriate parameters to reassemble these reads. Furthermore, we did not impose any restriction on the length of the sequences, i.e., removal of assembled contigs or reads less than a certain length (e.g., 200 bases), because such sequences could be part of the untranslated regions of many legitimate mRNA transcripts. As more similar EST sequences from closely related taxa become available, these short reads might ultimately be informative in the future. In summary, the TGICL assembly described in this paper only represents a generic, non-discriminatory clustering approach for the entire dataset, and re-assembling for the original ESTs might be necessary to produce the most accurate assembly for a given gene or a set of related genes.

\section{Conclusions}

We report the generation of 29,816 ESTs (7,464 unique clusters) from the Australian sheep blowfly Lucilia cuprina. Homology analyses revealed that the dataset captured a wide diversity of genes, including those related to insecticide resistance targets and detoxification gene families. Our data also indicate that $L$. cuprina coding sequences are AT rich and that codon usage patterns are distinct from that of D. melanogaster. In addition, a subset of putative orthologous genes was identified and mapped to the Lucilia linkage groups, 
which revealed a high but incomplete chromosomal synteny with $D$. melanogaster.

\section{Methods \\ Construction and sequencing of cDNA libraries}

Three cDNA libraries were constructed using RNA extracted from embryos, first-instar, and third-instar larvae. Construction of the embryonic cDNA library was previously described in Chen et al. (1998) [55]. Embryonic RNA was extracted from the non-modifier "seeking" strain using the Gibco-BRL mRNA Isolation System (Gaithersburg, MD). A unidirectional cDNA library was constructed in the EcoRI/XhoI sites of the $\lambda$ ZAP II vector (Stratagene, La Jolla, CA), and sequenced from the 5' end using the T3 primer and the 3' end using the T7 primer. Two larval cDNA libraries (first and third instar) were made using total RNA from the inbred laboratory $\mathrm{M}_{1} 5$ strain. cDNA was prepared using the SMART ${ }^{\mathbb{B}}$ cDNA library construction kit (Clontech Laboratories, Inc.), directionally cloned into the $\alpha$ TripIEx 2 vector via the $S f i$-I A/Sfi-I B restriction sites, and transformed into BM25.8 competent cells. Plasmid cDNA clones were sequenced from the 5' end using the Sp6 primer. All sequencing was completed using the Sanger dideoxy sequencing method at the Australian Genome Research Facility (AGRF) in Brisbane, Australia. Original EST reads were subject to standard quality-trimming, vectorremoval, and poly-A-clipping procedures. The output sequences were then assembled using the TGICL (TIGR Gene Indices clustering tools) algorithm [64] with the minimum threshold level set at $90 \%$ identity over a stretch of 50 bases.

\section{Homology comparison}

The GenBank non-redundant reference protein database $(8,328,903$ sequences) was downloaded from ftp://ftp.ncbi. nlm.nih.gov/blast/db/ in July 2010. The complete L. sericata mitochondrial genome (GI:154623433) [21] was also retrieved from Genbank. The 18,648 EST sequences from C. hominivorax (primary screwworm), 18, 797 EST sequences (generated by 454 GS FLX; SRA: SRA012250) from Stomoxys calcitrans (the stable fly), and 79,292 EST sequences from G. morsitans (tsetse fly) were batch downloaded from GenBank via the species taxonomy page in the National Center for Biotechnology Information (NCBI) http://www.ncbi.nlm.nih.gov/taxonomy/. The D. melanogaster and Anopheles gambiae proteome sequences were retrieved from FlyBase http://flybase.org/ and VectorBase http://www.vectorbase.org/, respectively. All sequences were converted into separate local databases using the NCBI standalone BLAST executables. Homology searches (BLASTX) were performed with E-value cut-off at $1 \mathrm{e}^{-10}$. To estimate gene coverage of our Lucilia dataset, we performed a BLASTX (E-value $\left.\leq 1 \mathrm{e}^{-10}\right)$ search against the D. melanogaster peptide database (r5.37). Due to the existence of isoforms in the BLASTX hit list, we extracted their corresponding gene identifiers (i.e., CG numbers and gene symbols) from FlyBase to estimate the number of unique genes. To identify putative orthologs among Lucilia, Drosophila and Anopheles, a more stringent BLAST Evalue threshold $\left(1 \mathrm{e}^{-50}\right)$ was used to retain only the most conserved homolog pairs. EST sequences that failed to find a significant match in the reference protein database were then used to search (BLASTN) against the L. sericata mitochondrial genome, the $C$. hominivorax and the G. morsitans sequences with E-value cutoff at $1 \mathrm{e}^{-10}$. Finally, a TBLASTX search (at E-value $<1 \mathrm{e}^{-10}$ ) was performed for EST sequences that did not find sequence homology in both the BLASTX and BLASTN searches.

\section{GC content and codon bias analyses}

To compare the GC content and codon usage properties between $L$. cuprina and D. melanogaster, we confined our analyses to 200 homologous sequence pairs. These 200 homologous pairs are highly conserved (BLASTX E-value $<1 \mathrm{e}^{-50}$ ) at the amino acid level and have identifiable complete open reading frames (ORFs) (see Additional file 3). Putative ORFs in Lucilia were extracted using the GENSCAN program developed by Burge and Karlin [65]. The homologous ORFs (or CDS) in D. melanogaster were retrieved from FlyBase http://flybase.org/static_pages/ downloads/ID.html. GC content and codon usage statistics were calculated using the GEECEE program http:// emboss.sourceforge.net/apps/cvs/emboss/apps/geecee. html. The effective Nc was estimated using the CHIP program http://emboss.sourceforge.net/apps/release/5.0/ emboss/apps/chips.html. All 3 programs were available at BioManager http://biomanager.info/ maintained by Peter Reeves at the University of Sydney, Australia.

\section{Pedigree construction}

The $M_{1} 5$ and the Tara strains were used to generate the male and female informative mapping families. The $M_{1} 5$ strain is highly inbred and carries 1 visible phenotypic marker on each of its 5 autosomes. The Tara strain (provided by Garry Levot) is a more recent field-derived strain that originated from Tara, Queensland, Australia. It is morphologically wild type and displays high levels of resistance to diflubenzuron and tolerance to cyromazine. To generate the male informative family TMM1, an F1 male from a single pair mating between an $\mathrm{M}_{1} 5$ male and a Tara female was backcrossed to a virgin $\mathrm{M}_{1} 5$ female (Figure 4).

\section{Choice of markers}

cDNA sequences (previously characterized genes and ESTs) were converted into gene markers for linkage analysis and synteny comparison. Marker selection was 
based on (1) their physical locations in D. melanogaster, to ensure an even coverage of all Muller's elements; (2) that these genes contain intron(s) of suitable size (100400 bases); and (3) that the intron positions are conserved in both $D$. melanogaster and A. gambiae. EPIC primers were designed using the Primer3 program http:// frodo.wi.mit.edu/primer3/ (see Additional file 9 for primer information).

\section{DNA isolation, polymerase chain reactions, and electrophoresis}

DNA from all individuals in the pedigrees was extracted using DNAzol ${ }^{\circledR}$ reagent (Invitrogen; Cat. No. 10503027). In subsequent genotyping assays, $0.1 \%$ of the whole body DNA in $1 \mu \mathrm{L}$ was used per PCR reaction. PCR was done in $25 \mu \mathrm{L}$ reactions, which contained $1 \mu \mathrm{L}$ of genomic DNA, $2.5 \mu \mathrm{L}$ of $10 \times$ reaction buffer, $3.0 \mu \mathrm{L}$ of $\mathrm{MgCl}_{2}$ at $25 \mathrm{mM}, 2.5 \mu \mathrm{L}$ of dNTPs at $2 \mathrm{mM}, 1 \mu \mathrm{L}$ of each of the forward and reverse primer at $10 \mu \mathrm{L}, 0.3 \mu \mathrm{L}$ of Taq DNA polymerase (Fermentas; Cat. No. EP0402), and 13.7 $\mu \mathrm{L}$ of nuclease-free water. We used a touchdown thermo-cycling strategy for all PCR amplification, which involved an initial denaturation step at $95^{\circ} \mathrm{C}$ for $5 \mathrm{~min}$, followed by 30 cycles of $95^{\circ} \mathrm{C}$ for $30 \mathrm{~s}, 65^{\circ} \mathrm{C}$ for $30 \mathrm{~s}$ (reduce $0.5^{\circ} \mathrm{C}$ per cycle), and $72^{\circ} \mathrm{C}$ for $2 \mathrm{~min}$, followed by another 30 cycles of $95^{\circ} \mathrm{C}$ for $30 \mathrm{~s}, 50^{\circ} \mathrm{C}$ for $30 \mathrm{~s}$, and $72^{\circ} \mathrm{C}$ for $2 \mathrm{~min}$. PCR amplicons were separated by electrophoresis.

The parents of the mapping crosses were first screened using EPIC primers for detectable size polymorphisms on a $1.2 \%$ agarose gel, which contained $1 \%$ agarose (Bioline; Cat. No. BIO-41025) and 0.2\% Ultra-High Resolution Agarose (Scientifix; Cat. No. 9030A), at $250 \mathrm{~V}$ for 25 min. However, if the agarose electrophoresis did not reveal intron size polymorphism, the PCR amplicons were heat denatured $\left(95^{\circ} \mathrm{C}\right.$ for $\left.3 \mathrm{~min}\right)$ and run on a $6 \%$ polyacrylamide gel (SequaGel ${ }^{\circledR}-6$ system, National Diagnostics; Cat. No. EC-836 and EC-841) at $500 \mathrm{~V}$ for $1.25 \mathrm{~h}$ using the Gel-Scan 2000 system (Corbett Research). The polyacrylamide gels were stained with $1 \times$ SYBRGold $^{\circledR} \mathrm{I}$ nucleic acid gel stain (Invitrogen; Cat. No. S-11494) to look for heteroduplex or single-strand conformation polymorphisms. If polymorphism was found in the parents of the mapping family, then identical procedures were applied to genotype the progeny.

\section{Linkage analysis}

Due to the general lack of meiotic crossing overs in dipteran males, markers on the same chromosome are transmitted together from the male parent to its progeny. Under our backcrossing schemes (Figure 4), all polymorphisms should have come from the Tara strain. Hence, the presence or absence of the Tara allele in the male informative family indicates the presence or absence of a specific Tara chromosome. Markers were assigned to the same linkage group if they shared identical segregation patterns in the male informative cross TMM1. Twenty-two backcross individuals from TMM1 were used in genotyping assays.

\section{Additional material}

\begin{abstract}
Additional file 1: $L$. cuprina non-redundant EST clusters. A sequence file containing 7,464 L. cuprina non-redundant EST clusters in FASTA format.

Additional file 2: L. cuprina mitochondrial genes. A sequence file containing consensus sequences of L. cuprina mitochondrial genes in FASTA format.

Additional file 3: Input file for GC and codon usage analyses. A sequence file containing 200 L. cuprina open reading frame sequences in FASTA format for GC and codon usage analyses.

Additional file 4: Homology search results. A table containing BLAST hits of the non-redundant 7,464 L. Cuprina EST sequences.

Additional file 5: InterProScan results. Two spreadsheets containing InterProScan terms captured by the L. cuprina EST sequences.

Additional file 6: Gene ontology results. Two spreadsheets containing Gene ontology terms captured by the L. cuprina EST sequences.

Additional file 7: BLAST-negative EST clusters with protein coding potential. A table containing a list of BLAST-negative EST clusters that have a hypothetical ORF of minimum 20 amino acids.

Additional file 8: Potential orthologous genes among L. cuprina, D. melanogaster and A. gambiae. A table containing accession numbers corresponding to orthologous genes among L. cuprina, D. melanogaster, and A. gambiae.

Additional file 9: Synteny between $L$. cuprina and $D$. melanogaster and primer information. A table containing chromosomal locations of L. cuprina genes and their corresponding primer sequences.
\end{abstract}

\section{Acknowledgements}

We thank Aysha Hill-Williams and Alex Blasetti for fly maintenance, Yoganand Sundaravadanam for bioinformatics support, and Matthew Johnson and Peter Wilson for sequencing support. The project was funded by the Australian Wool Innovation grant to P. Batterham and M. Scott and the Australia Research Council grants to P. Batterham.

\section{Author details}

${ }^{1}$ Centre for Environmental Stress and Adaptation Research, Bio21 Institute, Genetics Department, University of Melbourne, 30 Flemington Road, Parkville, VIC 3010, Australia. ${ }^{2}$ Australian Genome Research Facility, Level 5 Gehrmann Laboratories, University of Queensland, Research Road, St Lucia, QLD 4072, Australia.

\section{Authors' contributions}

SFL drafted the manuscript. ZC prepared the CDNA libraries and obtained the ESTs. SFL and ZC performed linkage mapping and quality control of the sequence assembly. AM performed the sequence assembly, gene ontology, and InterProScan. RTG performed homology searches. PB designed and supervised the project. All authors have read and approved the final manuscript.

Received: 11 March 2011 Accepted: 10 August 2011 Published: 10 August 2011

\section{References}

1. Paul AG, Ahmad NW, Lee HL, Ariff AM, Saranum M, Naicker AS, Osman Z: Maggot debridement therapy with Lucilia cuprina: a comparison with conventional debridement in diabetic foot ulcers. International wound journal 2009, 6(1):39-46. 
2. Tantawi Tl, Williams KA, Villet MH: An accidental but safe and effective use of Lucilia cuprina (Diptera: Calliphoridae) in maggot debridement therapy in Alexandria, Egypt. J Med Entomol 2010, 47(3):491-494.

3. Sherman RA: Maggot therapy for foot and leg wounds. The international journal of lower extremity wounds 2002, 1(2):135-142.

4. Williams $\mathrm{H}$ : A model for the aging of fly larvae in forensic entomology. Forensic science international 1984, 25(3):191-199.

5. Heath AC, Bishop DM: Flystrike in New Zealand: An overview based on a 16-year study, following the introduction and dispersal of the Australian sheep blowfly, Lucilia cuprina Wiedemann (Diptera: Calliphoridae). Vet Parasitol 2006, 137(3-4):333-344.

6. Watts JE, Murray MD, Graham NP: The blowfly strike problem of sheep in New South Wales. Aust Vet J 1979, 55(7):325-334.

7. Blackman GG, Bakker JA: Resistance of the sheep blowfly Lucilia cuprina to insecticides in the Republic of South Africa. J S Afr Vet Assoc 1975, 46(4):337-339.

8. Levot GW: Resistance and the control of sheep ectoparasites. International journal for parasitology 1995, 25(11):1355-1362

9. McKenzie JA: Dieldrin and diazinon resistance in populations of the Australian sheep blowfly, Lucilia cuprina, from sheep-grazing areas and rubbish tips. Aust J Biol Sci 1984, 37(5-6):367-374.

10. Shanahan GJ: Resistance to dieldrin in Lucilia cuprina Wied., the Australian sheep blowfly. Nature 1958, 181(4612):860-861.

11. McKenzie JA: Ecological and Evolutionary Aspects of Insecticide Resistance. Austin, Texas, U.S.A. R.G. Landes Company and Academic Press, Inc; 1996.

12. Newcomb RD, Campbell PM, Ollis DL, Cheah E, Russell RJ, Oakeshott JG: A single amino acid substitution converts a carboxylesterase to an organophosphorus hydrolase and confers insecticide resistance on a blowfly. Proceedings of the National Academy of Sciences of the United States of America 1997, 94(14):7464-7468.

13. Newcomb RD, Gleeson DM, Yong CG, Russell RJ, Oakeshott JG: Multiple mutations and gene duplications conferring organophosphorus insecticide resistance have been selected at the Rop-1 locus of the sheep blowfly, Lucilia cuprina. J Mol Evol 2005, 60(2):207-220.

14. Ullerich FH, Schottke M: Karyotypes, constitutive heterochromatin, and genomic DNA values in the blowfly genera Chrysomya, Lucilia, and Protophormia (Diptera: Calliphoridae). Genome 2006, 49(6):584-597.

15. Bedo DG: Polytene chromosomes of the Old World screwworm fly (Chrysomya bezziana) and its evolutionary relationships with Lucilia cuprina and Cochliomyia hominivorax (Diptera: Calliphoridae). Genome 1992, 35(2):294-303.

16. Perkins HD, Bedo DG, Howells AJ: Characterization and chromosomal distribution of a tandemly repeated DNA sequence from the Australian sheep blowfly, Lucilia cuprina. Chromosoma 1992, 101(5-4):358-364.

17. Foster GG, Whitten MJ, Konovalov C, Arnold JTA, Maffi G: Autosomal genetic maps of the Australian Sheep Blowfly, Lucilia cuprina dorsalis R.D. (Diptera: Calliphoridae), and possible correlations with the linkage maps of Musca domestica L. and Drosophila melanogaster (Mg.). Genetical Research 1981, 37:55-69.

18. Weller GL, Foster GG: Genetic maps of the sheep blowfly Lucilia cuprina: linkage-group correlations with other dipteran genera. Genome 1993, 36(3):495-506.

19. Guerrero FD, Dowd SE, Djikeng A, Wiley G, Macmil S, Saldivar L, Najar F, Roe BA: A database of expressed genes from Cochliomyia hominivorax (Diptera: Calliphoridae). Journal of medical entomology 2009, 46(5):1109-1116.

20. Attardo GM, Strickler-Dinglasan P, Perkin SA, Caler E, Bonaldo MF, Soares MB, El-Sayeed N, Aksoy S: Analysis of fat body transcriptome from the adult tsetse fly, Glossina morsitans morsitans. Insect molecular biology 2006, 15(4):411-424.

21. Stevens JR, West $H$, Wall R: Mitochondrial genomes of the sheep blowfly, Lucilia sericata, and the secondary blowfly, Chrysomya megacephala. Med Vet Entomol 2008, 22(1):89-91.

22. ffrench-Constant RH, Steichen JC, Rocheleau TA, Aronstein K, Roush RT: A single-amino acid substitution in a gamma-aminobutyric acid subtype $A$ receptor locus is associated with cyclodiene insecticide resistance in Drosophila populations. Proceedings of the National Academy of Sciences of the United States of America 1993, 90(5):1957-1961.
23. Hope $M$, Menzies $M$, Kemp D: Identification of a dieldrin resistanceassociated mutation in Rhipicephalus (Boophilus) microplus (Acari: Ixodidae). J Econ Entomol 2010, 103(4):1355-1359.

24. Narahashi T: Neuronal Ion Channels as the Target Sites of Insecticides. Pharmacology \& Toxicology 1996, 79(1):1-14.

25. Raymond-Delpech V, Matsuda K, Sattelle BM, Rauh JJ, Sattelle DB: Ion channels: molecular targets of neuroactive insecticides. Invert Neurosci 2005, 5(3-4):119-133.

26. Adams MD, Celniker SE, Holt RA, Evans CA, Gocayne JD, Amanatides PG, Scherer SE, Li PW, Hoskins RA, Galle RF, George RA, Lewis SE, Richards S, Ashburner M, Henderson SN, Sutton GG, Wortman JR, Yandell MD, Zhang Q, Chen LX, Brandon RC, Rogers YH, Blazej RG, Champe M, Pfeiffer BD, Wan KH, Doyle C, Baxter EG, Helt G, Nelson CR, et al: The genome sequence of Drosophila melanogaster. Science 2000, 287(5461):2185-2195.

27. Vicario S, Moriyama EN, Powell JR: Codon usage in twelve species of Drosophila. BMC evolutionary biology 2007, 7:226.

28. Coates CJ, Howells AJ, O'Brochta DA, Atkinson PW: The 5' regulatory region from the Drosophila pseudoobscura hsp82 gene results in a high level of reporter gene expression in Lucilia cuprina embryos. Gene 1996, 175(1-2):199-201

29. Heinrich JC, Li X, Henry RA, Haack N, Stringfellow L, Heath AC, Scott MJ: Germ-line transformation of the Australian sheep blowfly Lucilia cuprina. Insect molecular biology 2002, 11(1):1-10.

30. Scott MJ, Heinrich JC, Li X: Progress towards the development of a transgenic strain of the Australian sheep blowfly (Lucilia cuprina) suitable for a male-only sterile release program. Insect biochemistry and molecular biology 2004, 34(2):185-192.

31. Bagnall NH, Kotze AC: Evaluation of reference genes for real-time PCR quantification of gene expression in the Australian sheep blowfly, Lucilia cuprina. Med Vet Entomol 2010, 24(2):176-181.

32. Inosaki A, Yasuda A, Shinada T, Ohfune $Y$, Numata H, Shiga S: Mass spectrometric analysis of peptides in brain neurosecretory cells and neurohemal organs in the adult blowfly, Protophormia terraenovae. Comparative biochemistry and physiology 2010, 155(2):190-199.

33. Le Goff G, Boundy S, Daborn PJ, Yen JL, Sofer L, Lind R, Sabourault C, MadiRavazzi $L$, ffrench-Constant RH: Microarray analysis of cytochrome P450 mediated insecticide resistance in Drosophila. Insect biochemistry and molecular biology 2003, 33(7):701-708.

34. Low WY, Feil SC, Ng HL, Gorman MA, Morton CJ, Pyke J, McConville MJ, Bieri M, Mok YF, Robin C, Gooley PR, Parker MW, Batterham P: Recognition and detoxification of the insecticide DDT by Drosophila melanogaster glutathione S-transferase D1. Journal of molecular biology 2010, 399(3):358-366.

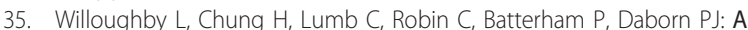
comparison of Drosophila melanogaster detoxification gene induction responses for six insecticides, caffeine and phenobarbital. Insect biochemistry and molecular biology 2006, 36(12):934-942.

36. Chung H, Sztal T, Pasricha S, Sridhar M, Batterham P, Daborn PJ: Characterization of Drosophila melanogaster cytochrome P450 genes. Proceedings of the National Academy of Sciences of the United States of America 2009, 106(14):5731-5736.

37. Chavez VM, Marques G, Delbecque JP, Kobayashi K, Hollingsworth M, Burr J, Natzle JE, O'Connor MB: The Drosophila disembodied gene controls late embryonic morphogenesis and codes for a cytochrome P450 enzyme that regulates embryonic ecdysone levels. Development 2000, 127(19):4115-4126

38. Warren JT, Petryk A, Marques G, Jarcho M, Parvy JP, Dauphin-Villemant C, $\mathrm{O}$ 'Connor MB, Gilbert LI: Molecular and biochemical characterization of two P450 enzymes in the ecdysteroidogenic pathway of Drosophila melanogaster. Proceedings of the National Academy of Sciences of the United States of America 2002, 99(17):11043-11048.

39. Maibeche-Coisne M, Monti-Dedieu L, Aragon S, Dauphin-Villemant C: A new cytochrome P450 from Drosophila melanogaster, CYP4G15, expressed in the nervous system. Biochemical and biophysical research communications 2000, 273(3):1132-1137.

40. Low WY, Ng HL, Morton CJ, Parker MW, Batterham P, Robin C: Molecular evolution of glutathione S-transferases in the genus Drosophila. Genetics 2007, 177(3):1363-1375. 
41. Ranson H, Claudianos C, Ortelli F, Abgrall C, Hemingway J, Sharakhova MV Unger MF, Collins FH, Feyereisen R: Evolution of supergene families associated with insecticide resistance. Science 2002, 298(5591):179-181.

42. Tijet N, Helvig C, Feyereisen R: The cytochrome P450 gene superfamily in Drosophila melanogaster: annotation, intron-exon organization and phylogeny. Gene 2001, 262(1-2):189-198.

43. Vogel H, Heidel AJ, Heckel DG, Groot AT: Transcriptome analysis of the sex pheromone gland of the noctuid moth Heliothis virescens. BMC genomics 2010, 11:29.

44. Khajuria C, Zhu YC, Chen MS, Buschman LL, Higgins RA, Yao J, Crespo AL, Siegfried BD, Muthukrishnan S, Zhu KY: Expressed sequence tags from larval gut of the European corn borer (Ostrinia nubilalis): exploring candidate genes potentially involved in Bacillus thuringiensis toxicity and resistance. BMC genomics 2009, 10:286.

45. Walters JR, Harrison RG: EST analysis of male accessory glands from Heliconius butterflies with divergent mating systems. BMC genomics 2008, 9:592.

46. O'Neil ST, Dzurisin JD, Carmichael RD, Lobo NF, Emrich SJ, Hellmann JJ: Population-level transcriptome sequencing of nonmodel organisms Erynnis propertius and Papilio zelicaon. BMC genomics 2010, 11:310.

47. Vera JC, Wheat CW, Fescemyer HW, Frilander MJ, Crawford DL, Hanski I, Marden JH: Rapid transcriptome characterization for a nonmodel organism using 454 pyrosequencing. Molecular ecology 2008, 17(7):1636-1647

48. Ferguson L, Lee SF, Chamberlain N, Nadeau N, Joron M, Baxter S, Wilkinson P, Papanicolaou A, Kumar S, Kee TJ, Clark R, Davidson C, Glithero R, Beasley $H$, Vogel H, ffrench-Constant R, Jiggins C: Characterization of a hotspot for mimicry: assembly of a butterfly wing transcriptome to genomic sequence at the HmYbSb locus. Molecular ecology 2010, 19(Suppl 1):240-254.

49. Beldade P, Saenko SV, Pul N, Long AD: A gene-based linkage map for Bicyclus anynana butterflies allows for a comprehensive analysis of synteny with the lepidopteran reference genome. PLOS genetics 2009, 5(2):e1000366.

50. Yasukochi Y, Ashakumary LA, Baba K, Yoshido A, Sahara K: A secondgeneration integrated map of the silkworm reveals synteny and conserved gene order between lepidopteran insects. Genetics 2006, 173(3):1319-1328.

51. Roethele JB, Feder JL, Berlocher SH, Kreitman ME, Lashkari DA: Toward a molecular genetic linkage map for the apple maggot fly (Diptera: Tephritidae): Comparison of alternative strategies. Ann Entomol Soc Am 1997, 90(4):470-479.

52. Severson DW, Mori A, Kassner VA, Christensen BM: Comparative linkage maps for the mosquitoes, Aedes albopictus and Ae. aegypti, based on common RFLP loci. Insect molecular biology 1995, 4(1):41-45.

53. Bhutkar A, Schaeffer SW, Russo SM, Xu M, Smith TF, Gelbart WM: Chromosomal rearrangement inferred from comparisons of 12 Drosophila genomes. Genetics 2008, 179(3):1657-1680.

54. Zdobnov EM, von Mering C, Letunic I, Torrents D, Suyama M, Copley RR, Christophides GK, Thomasova D, Holt RA, Subramanian GM, Mueller HM, Dimopoulos G, Law JH, Wells MA, Birney E, Charlab R, Halpern AL, Kokoza E, Kraft CL, Lai Z, Lewis S, Louis C, Barillas-Mury C, Nusskern D, Rubin GM, Salzberg SL, Sutton GG, Topalis P, Wides R, Wincker P, et al: Comparative genome and proteome analysis of Anopheles gambiae and Drosophila melanogaster. Science 2002, 298(5591):149-159.

55. Chen Z, Newsome T, McKenzie JA, Batterham P: Molecular characterization of the Notch homologue from the Australian sheep blowfly, Lucilia cuprina. Insect biochemistry and molecular biology 1998, 28(8):601-612.

56. Davies AG, Game AY, Chen Z, Williams TJ, Goodall S, Yen JL, McKenzie JA, Batterham P: Scalloped wings is the Lucilia cuprina Notch homologue and a candidate for the modifier of fitness and asymmetry of diazinon resistance. Genetics 1996, 143(3):1321-1337.

57. Russell RJ, Robin GC, Kostakos P, Newcomb RD, Boyce TM, Medveczky KM, Oakeshott JG: Molecular cloning of an alpha-esterase gene cluster on chromosome 3R of Drosophila melanogaster. Insect biochemistry and molecular biology 1996, 26(3):235-247.

58. Rose CJ, Chapman J, Marshall SD, Lee SF, Batterham P, Ross HA Newcomb RD: Selective sweeps at the organophosphorus insecticide resistance locus, Rop-1, have affected variation across and beyond the \{alpha\}-esterase gene cluster in the Australian sheep blowfly, Lucilia cuprina. Molecular biology and evolution 2011, 28(6):1835-1846.
59. McKenzie JA, Game AY: Diazinon resistance in Lucilia cuprina; mapping of a fitness modifier. Heredity 1987, 59:371-381.

60. McKenzie JA, Purvis A: Chromosomal localisation of fitness modifiers of diazinon resistance genotypes of Lucilia cuprina. Heredity 1984, 53:625-634.

61. McKenzie JA, Whitten MJ, Adena MA: The effect of genetic background on the fitness of diazinon resistance genotypes of the Australian sheep blowfly, Lucilia cuprina. Heredity 1982, 49:1-9.

62. Stevens JR: The evolution of myiasis in blowflies (Calliphoridae). International journal for parasitology 2003, 33(10):1105-1113.

63. Harvey ML, Gaudieri S, Villet MH, Dadour IR: A global study of forensically significant calliphorids: implications for identification. Forensic science international 2008, 177(1):66-76.

64. Pertea G, Huang X, Liang F, Antonescu V, Sultana R, Karamycheva S, Lee $Y$, White J, Cheung F, Parvizi B, Tsai J, Quackenbush J: TIGR Gene Indices clustering tools (TGICL): a software system for fast clustering of large EST datasets. Bioinformatics 2003, 19(5):651-652.

65. Burge C, Karlin S: Prediction of complete gene structures in human genomic DNA. Journal of molecular biology 1997, 268(1):78-94.

doi:10.1186/1471-2164-12-406

Cite this article as: Lee et al:: Identification, analysis, and linkage mapping of expressed sequence tags from the Australian sheep blowfly. BMC Genomics 2011 12:406.

\section{Submit your next manuscript to BioMed Central and take full advantage of:}

- Convenient online submission

- Thorough peer review

- No space constraints or color figure charges

- Immediate publication on acceptance

- Inclusion in PubMed, CAS, Scopus and Google Scholar

- Research which is freely available for redistribution

Submit your manuscript at www.biomedcentral.com/submit
Biomed Central 